\title{
CUBIC AND QUADRATIC POLYNOMIAL ON JULIA SET WITH TRIGONOMETRIC FUNCTION
}

\author{
Jullia Titaley $^{\left.1^{*}\right)}$, Tohap Manurung ${ }^{1)}$, Henriette D. Titaley ${ }^{2)}$ \\ ${ }^{1)}$ Department of Mathematics, Sam Ratulangi University \\ ${ }^{2}$ Department of Engineering, Politeknik Negeri Ambon \\ *Corresponding author: july.titaley@gmail.com
}

\begin{abstract}
Julia set are defined by iterating a function of a complex number and is generated from the iterated function $f_{c}(z)=z_{n}^{2}+c$. We investigate in this paper the complex dynamics of different functions and applied iteration function system to generate an entire new class of julia set. The purpose of this research is to make variation of Cubic and Quadratic polynomial on Julia Set and the two obvious to investigate from julia set are Sine and Cosine function. The results thus obtained are innovative and studies about different behavior of two basic trigonometry.
\end{abstract}

Keywords : Julia Set, trigonometric function, polynomial function

\section{POLINOMIAL KUBIK DAN KUADRATIK PADA HIMPUNAN JULIA DENGAN FUNGSI TRIGONOMETRI}

\begin{abstract}
ABSTRAK
Himpunan Julia didefiniskan oleh fungsi iterasi dari bilangan kompleks dan dibangkitkan dari fungsi iterasi $f_{c}(z)=z_{n}^{2}+c$. Kami melakukan penelitian dalam penulisan ini tentang sistem dinamik kompleks dari fungsi yang berbeda dengan iterasi yang diterapkan untuk menghasilkan kelas baru dari himpunan Julia. Tujuan dari penelitian ini adalah untuk membuah kelas baru himpunan Julia dengan fungsi polinomial kubik dan kuadratik dengan fungsi sinus dan kosinus. Hasil akhir dari penelitian ini ada menemukan inovatif baru dari himpunan Julia dengan menggunakan dua fungsi trigonometri.
\end{abstract}

Kata kunci : Julia Set, fungsi trigonometri, fungsi polinomial

\section{INTRODUCTION}

In mathematics, a fractal is an abstract object used to describe and simulate naturally occuring objects. Julia sets can be simple (like a circle) or extremely complicated like a fractal. Interesting facts about Julia sets and related mathematics began in the 1920's with Gaston Julia ( Devaney, 1989). His extraordinary talents were recognized from an early age and altough in every subject. Julia sets are defined by iterating a function of a complex number. Julia sets have been studied for quadratic (Ishikawa et al., 1974 and Chauhan et al., 2010) and also for higher degree polynomials. Pick a point in the complex plane (i.e.., a complex number; these can be represented as a point

$$
z=(x, y) \text { in }
$$

the plane). Iterate the function starting at this point.

Having had a look at the fun that can be had with fractals based on $\mathrm{Z}$ $f_{n+1}(z)=z_{n}^{2}+c$. What happens when we start with functions borrowed from trigonometry? The two obvious functions to investigate in this research are sine and cosine function. Research by Kodri and Titaley (2017) was to produce a combination of Batik Minahasa based on julia set. The results show that by selecting a complex number $c=a+b i$ within a range of $-2 \leq$ $a \leq 2$ and $-2 \leq b \leq 2$ gives interesting shapes of Julia sets. The key feature of this paper is to show that the trigonometric functions, which falls under category of trancendental function is an example, where Julia set is all of C. 
Recently, Ashish et al., (2013) generated study of cubic Julia sets in NO and took the shapes of Christmas tree, Sikh Mythological symbol Khanda and wall decorative picture.

The study of dynamical behaviour of transcendental functions were initiated by Fatou (Fatou, 1926). For transcendental function, points with unbounded orbits are not in Fatou sets but they must lie in Julia sets. Attractive points of a function have a basic of attraction, which may be disconnected.

A Julia set thus, satisfies the following properties:

(i) Closed

(ii) Nonempty

(iii) Forward

(iv) Backward invariant

(v) Equal to the closure of the set of repelling cycles of $F$

In other words, Fatou set is the complement set of Julia set, also stated as stable set.

Thus, the iteration of complex analytic function $\mathrm{F}$ decompose the complex plane into two disjoint sets.

1. Stable Fatou sets in which iterates are well behaved.

2. Julia sets on which the map is chaotic In trigonometric functions, $G(z)=$ $\sin z, 0$ is defined as fixed point for $G$. If $x_{0} \in$ $R$, then either $G\left(x_{0}\right)=0$ or $G^{n}\left(x_{0}\right) \rightarrow 0$. Also, we have the points lying on the imaginary axis have their orbits that tend to infinity (Fatou, 1926)

The other orbits which escpaes for cosine function, if $\left[C_{\gamma}^{n}(z)\right] \rightarrow \infty$ as $n \rightarrow \infty$, then orbit which escapes do so, with the increase in the imaginary part. Sine and cosine functions are thus declared as Topologically complete (Ishikawa, 1974).

The fixed point in topology, $z=z_{0}$ is declared as

- Attracting if $0<\left|F^{\prime}\left(z_{0}\right)\right|<1$

- Superattracting if $F^{\prime\left(z_{0}\right)}=0$

- Repelling if $\left|F^{\prime}\left(z_{0}\right)\right|>1$

- Neutral if $F^{\prime\left(z_{0}\right)}=e^{i 2 \pi \theta_{0}}$

If $\theta_{0}$ is rational, then $z_{0}$ is rationally indifferent or parabolic, otherwise $z_{0}$ is irrationally indifferent.
We introduce in this paper trigonometric functions of the type $\left\{\sin \left(z^{n}\right)+c\right\}$ and $\left\{\cos \left(z^{n}\right)+c\right\}$ and applied iterated function system to develop an entirely new class of Julia set.

Which gives the escape criterion for cubic polynomial

\section{MATERIALS AND METHODS}

The process of generating Julia set images from $z \rightarrow \sin \left(z^{n}\right) * c$ and $z \rightarrow \cos \left(z^{n}\right) *$ $c$ is similar to the one employed for the selfsquared function This process consists of iterating this function up to $\mathrm{N}$ times. Starting from a value $z_{0}$ we obtain $z_{1}, z_{2}, z_{3}, \ldots$ by applying the transformations $z \rightarrow \sin \left(z^{n}\right) * c$ and $z \rightarrow \cos \left(z^{n}\right) * c$ one by one respectively.

Method of research is

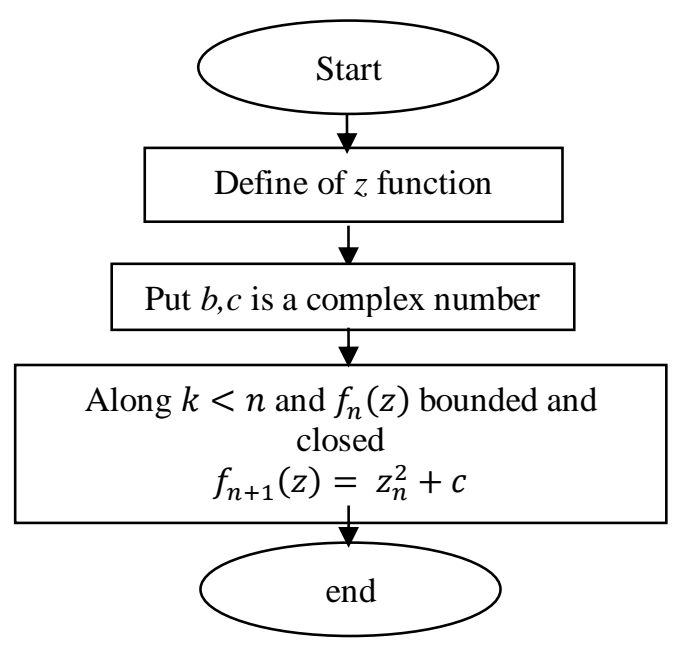

Fig.1 Flowchart of Julia set

\section{RESULTS AND DISCUSSION}

Using the computational work in Matlab, we generated Julia sets for cubic polynomials with trigonometric function. We iterated the cubic polynomial $z \rightarrow z^{3}+a z+$ $b$, where $a$ and $b$ are complex number with iterative function system.

Which gives the Escape criterion for the following cubic polynomials :

$$
F_{m, n}(z)=z^{3}+a z+b
$$

Where $a$ and $b$ are complex numbers.

Theorem 1. Let $|z|>|b|>(|a|+2 /|\alpha|),|z|>$ $|b|>(|a|+2 / \gamma)^{1 / 2} \quad$ exist, where $0<\alpha<$ $1,0<\beta<1,0<\gamma<1$. 


\section{Escape Criterion for Cubics :.}

Let $\quad|z|>|n|>(|b|+2 /|\alpha|)^{1 / 2},|z|>|c|>$ $(|b|+2 /|\beta|)^{1 / 2}$ and $|z|>|c|>(|b|+2 /|\gamma|)^{1 / 2}$ exists, where $0<\alpha<1,0<\beta<1.0<\gamma<1$. This gives an escape criterion for cubic polynomials.

\section{General Escape Criterion :}

Suppose $|z|>\max |n|>(|b|+2 /|\alpha|)^{1 / 2},(|b|+$ $2 /|\beta|)^{1 / 2},(|b|+2 /|\gamma|)^{1 / 2}$ then $\left|z_{k}\right| \rightarrow \infty$ as $k \rightarrow$ $\infty$

\section{Generating the fractal motifs}

The fractal generated from equation $z \rightarrow$ $\cos \left(z^{n}\right) * c$ possesses symetry along the real axis.

- In case of a quadratic polynomial..

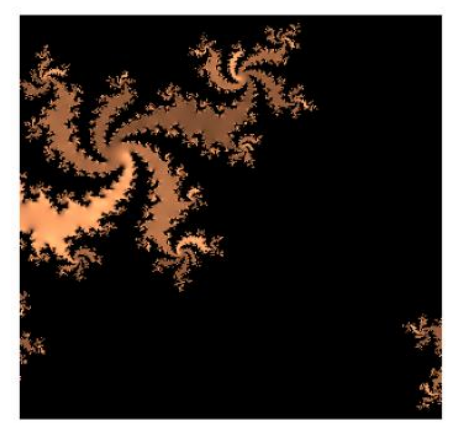

Fig 2. Quadratic Julia set with $c=-0.54-0.54123 \mathrm{i}$

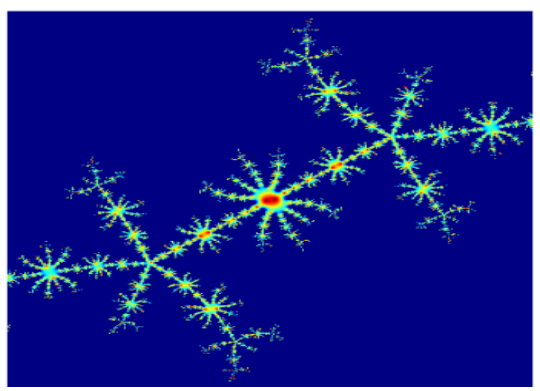

Fig 3. Quadratic Julia set with $c=-0.561321+0.6410000 \mathrm{i}$

- In case of a cubic polynomial, the central body is divided into two equal parts, each part containing one mayor secondary lobe and many minor secondary lobes

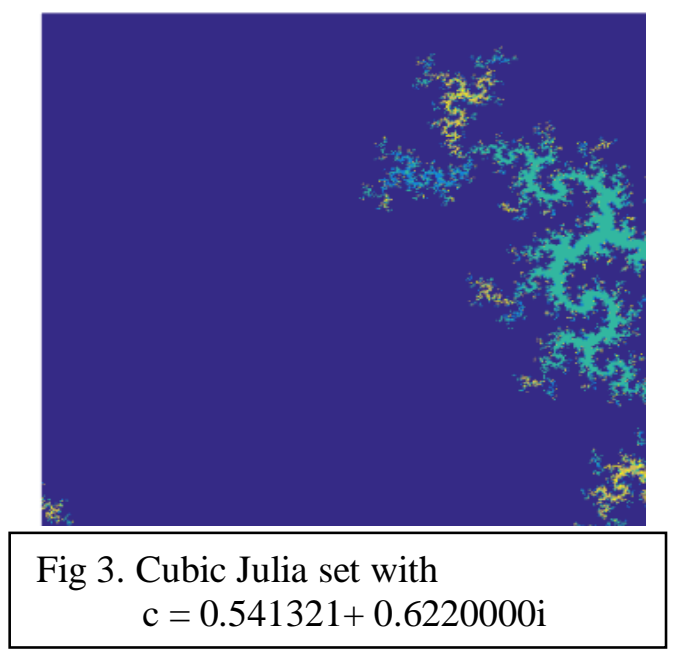

Fixed Points of cosine function Quadratic polynomial

Table 1. Orbit of $F(z)$ for

\begin{tabular}{|c|c|c|c|}
\multicolumn{4}{|c|}{$c=-0.561321+0.6410000 \mathrm{i}$} \\
\hline $\begin{array}{c}\text { Number } \\
\text { of } \\
\text { Iteration } \\
\mathbf{i}\end{array}$ & $\mathbf{F}(\mathbf{z})$ & $\begin{array}{c}\text { Number } \\
\text { of } \\
\text { Iteration } \\
\mathbf{i}\end{array}$ & $\mathbf{F}(\mathbf{z})$ \\
\hline 1 & 0.5516 & 11 & 0.5437 \\
\hline 2 & 0.5508 & 12 & 0.5437 \\
\hline 3 & 0.4484 & 13 & 0.5437 \\
\hline 4 & 0.6035 & 14 & 0.5437 \\
\hline 5 & 0.4959 & 15 & 0.5437 \\
\hline 6 & 0.4081 & 16 & 0.5437 \\
\hline 7 & 0.4348 & 17 & 0.5437 \\
\hline 8 & 0.5918 & 18 & 0.5437 \\
\hline 9 & 0.5312 & 19 & 0.5437 \\
\hline 10 & 0.4503 & 20 & 0.5437 \\
\hline
\end{tabular}

The fractal generated from equation $z \rightarrow$ $\sin \left(z^{n}\right) * c$ possesses symetry along the real axis.

- In case of a quadratic polynomial..

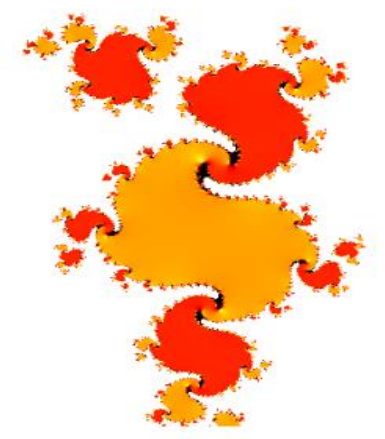

Fig 4. Quadratic Julia set with $c=-0.38765765-0.68754 \mathrm{i}$ 


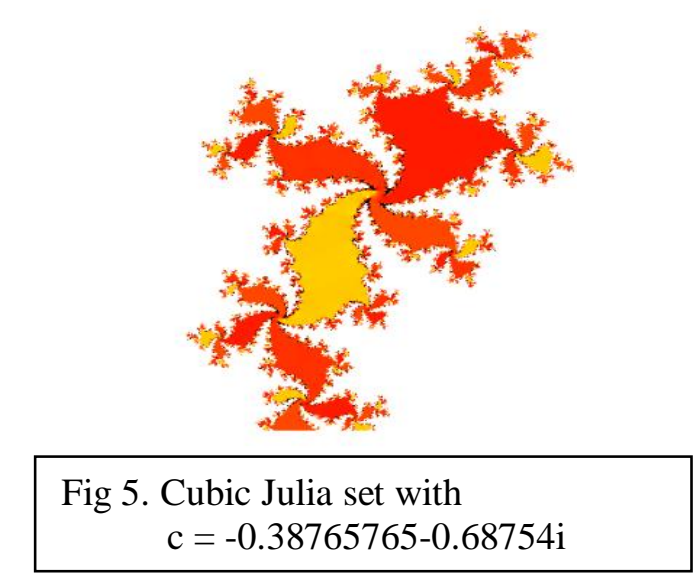

\section{CONCLUSION}

Julia set is collection limit of several points between escape set and prison set. In this paper we studied the cosine function which is one of the members of trancendental family. Orbit for this function on the real axis tend to 0 , but on the imaginary axis tends to infinity. The results thus obtained are innovative and studies about different behavior of two basic trigonometry.

\section{Acknowledgments}

This reserarch was partially funded supported by the Sam Ratulangi University Grant.

\section{REFERENCES}

Ashish, M. Rani and R. Chugh. 2013. Study of Cubic Julia Sets in NO. Journal of Computational Science \& Technology 1(1): 13-17.

Chauhan, Y.S., R. Rana and Ashish Negi. 2010. New Julia Sets of Ishikawa Iterates. International Journal of Computer Applications (0975-8887), 7(13): 34-42.

Devaney, R.L. 1989. An Introduction to Chaotic Dynamical Systems, $2^{\text {nd }}$ Edition. Perseus Books Publishing, Reading, MA.

Fatou, P. 1926. Sur Iteration des functions trnasendantes entires. Acta Math 47: 337-378.

Ishikawa, S. 1974. Fixed Points by a new iteration method. Proc.Amer.Math.Soc 44: 147-150.
Kodri, R.F. and J. Titaley. 2017. Variation of Batik Minahasa based on Julia set. Journal of MIPA UNSRAT online 6(2): 81-85. 